\title{
Why inequality is fatal
}

The Spirit Level: Why More Equal Societies

Almost Always Do Better

by Richard Wilkinson and Kate Pickett

Allen Lane: 2009.320 pp. $€ 20$

Why are our chances of reaching a great age so affected by wealth and status? The obvious answer is that more income buys better health. But it is a lot more subtle than that, as shown three decades ago by the Whitehall Study, in which epidemiologist Michael Marmot examined the death rates of British civil servants. To the surprise of many, he found that his subjects - all in continuous paid employment and with equal access to health care - were more likely to die in any given year if they were in a lower-grade job than a higher one. Marmot concluded that the employment hierarchy itself created status-dependent stress that affected the workers' health.

In their new book, epidemiologists Richard Wilkinson and Kate Pickett extend this idea with a far-reaching analysis of the social consequences of income inequality. Using statistics from reputable independent sources, they compare indices of health and social development in 23 of the world's richest nations and in the individual US states. Their striking conclusion is that the societies that do best for their citizens are those with the narrowest income differentials — such as Japan and the Nordic countries and the US state of New Hampshire. The most unequal the United States as a whole, the United Kingdom and Portugal - do worst.

Many measures of the quality of life, including life expectancy, are correlated with the degree of economic equality in each country. A variety of problems such as mental illness, obesity, cardiovascular disease, unwillingness to engage with education, misuse of illegal and prescription drugs, teenage pregnancy, lack of social mobility and neglect of child welfare increase with greater inequality. Violence, from murder to the bullying of children at school, follows the same pattern. These trends are tied up with issues of trust: the authors chart a profound decline in trust in the United States from the 1960 s to the present, which matches rising inequality during the long Republican ascendancy. The only statistic that defies the general trend is that for suicide, the incidence of which is higher in the most egalitarian countries, such as Sweden and Japan. Those

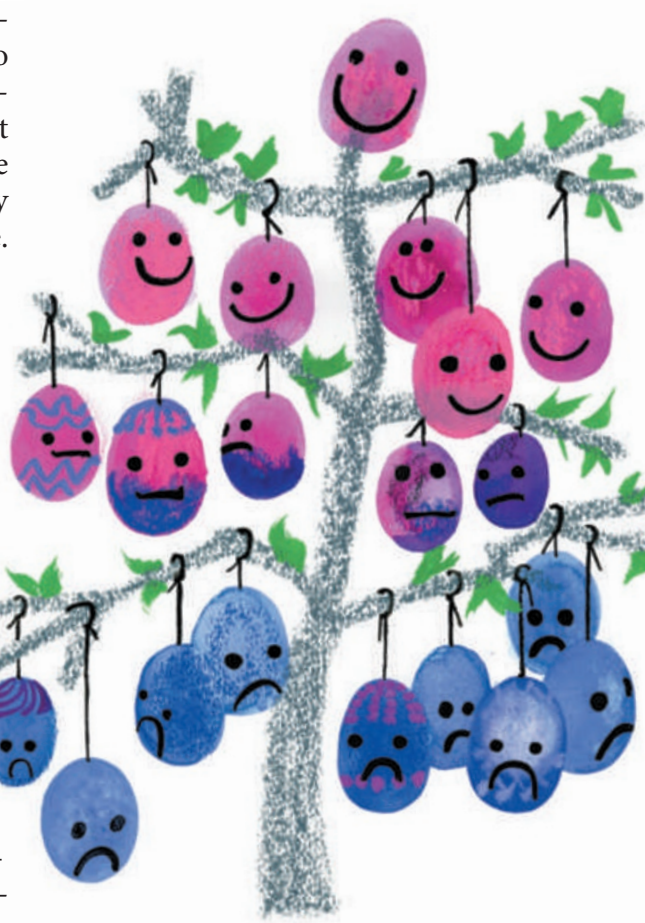

who feel out of step with their country seem to blame themselves and not others.

The idea that income inequality within a society is more unsettling to health and welfare than income differences between societies has been hotly debated for more than two decades. In the past year alone, six academic analyses have been published in peer-reviewed journals, four of which contradict the hypothesis on statistical grounds. Yet Wilkinson and Pickett do not address these criticisms in their book. They might also have explained the occasional notable deviation from their theory, such as the unexpectedly high murder rates in egalitarian Finland and the unexpectedly low rates in very unequal Singapore.

How can inequality affect such a diverse set of social problems so profoundly? The authors make a compelling case that the key is neuroendocrinological stress, provoked by a perception that others enjoy a higher status than oneself, undermining self-esteem. This triggers the release of the hormone cortisol, which raises blood pressure and blood sugar levels, from which myriad health and social problems unfold. This seemingly hard-wired response has been well studied in social hierarchies of monkeys; low-status animals become predisposed to atherosclerosis and cardiovascular disease. Humans experiencing chronic stress exhibit similar symptoms, accumulating abdominal fat under the influence of a part of the brain associated with addiction.

Cortisol overrides 'feel-good hormones' such as oxytocin, involved in establishing trust, and dopamine, the reward signal that reinforces memory, attention and problem-solving ability. Cortisol-induced stress predisposes some individuals to mental illness or violent behaviour. It can hasten the arrival of puberty, which may prompt premature sexual adventures, providing a plausible explanation of the high prevalence of teenage pregnancies in the most unequal societies. Cortisol also transmits stress to a fetus, with lasting consequences for physical and emotional development.

The stress response could even exacerbate illiteracy and unwillingness to engage with education. Wilkinson and Pickett argue that these are more common in less equal societies, not because of poverty but because school-age students may lose self-esteem when they realize that some of their peers are better equipped than themselves for educational challenges. The stress response may also lead to illicit drug use. Monkey social hierarchies provide a clue: dominant animals secrete dopamine and feel

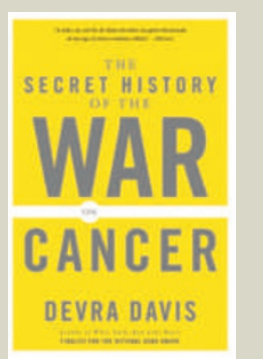

The Secret History of the War on Cancer by Devra Davis

(Basic Books, E10.99)

Drawing on research and personal experience, Devra

Davis argues that focusing on cancer treatment instead of prevention has cost lives. Reviewer Daniel S. Greenberg wrote, "For a well-documented, prosecutorial account of the dark side of cancer-control politics, Davis's work - lopsided and verbose as it is merits attention." (Nature 449, 660-661; 2007).

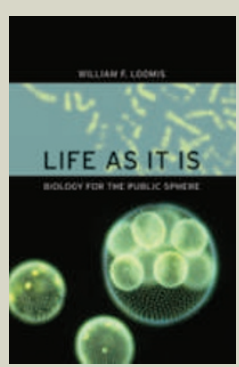

Life As It Is: Biology for the Public Sphere by William F. Loomis (Univ. California Press, \$15.95) William F. Loomis explores controversial issues from a biological perspective, providing "a fascinating, if occasionally disjointed, survey of topics ... the nature and evolution of life, and current scientific thought regarding consciousness, psychology and social behaviour." (Eugenie Scott, Nature 452, 690-691; 2008). 
good about their place in the world, whereas monkeys at the other end of the status scale are more inclined to self-medicate - with cocaine if given the opportunity.

The Spirit Level is a brave and imaginative effort to understand the intractable social problems that face rich democratic countries. For Wilkinson and Pickett, economic equality is the best way to improve the quality of life for all. Governments can get there by using redistributive taxation and an extensive welfare state, as in Sweden, or by restraining income disparities and minimizing public spending, as in Japan. The book ends optimistically: whatever route is chosen, the authors argue, the current economic slump may be a providential opportunity to start righting the balance. Michael Sargent is a developmental biologist at the National Institute for Medical Research in London and is author of Biomedicine and the Human Condition: Challenges, Risks and Rewards. e-mail: msargen@nimr.mrc.ac.uk

\section{Fiction beyond the grave}

\section{Sum: Forty Tales from the Afterlives by David Eagleman}

Pantheon: 2009.107 pp. $\$ 20.00$

There is no life after death. When our bodies fail, our minds go with them, and the game is over. Or is it?

Sum gathers 40 playful sketches of what an afterlife might hold for us, from expanding into a nine-dimensional cloud to working as an extra in other people's dreams. As rigorous and imaginative as the writings of Italo Calvino and Alan Lightman, each vignette is a glimpse into an expansive topic such as time, faith or memory. Together they illuminate an astounding range of possibilities for the meaning of human life.

Neuroscientist David Eagleman has written these fictional scenarios in parallel with a number of his popular science books about the brain, and while running a laboratory at Baylor College of Medicine in Houston, Texas. His research on time perception may have inspired some of his literary conceits. In the title story, a lifetime of activities is sorted into insufferable batches -30 years of sleep, 200 days in the shower, 18 days staring into the refrigerator - suggesting that it is the transitions between experiences that make life worth living.

The book includes, as one might expect, a round of fables that deflate Christian stereotypes of the hereafter. In some, paradise is vulnerable to the petty vices of men - holy war, bickering, bureaucracy, even communism - which makes these versions of heaven more like comic varieties of hell. In another, God is revealed to be an opportunistic tinkerer who doesn't understand His own creation.

Eagleman is at his sharpest when he envisions efforts to evade death using science. In one tale, a doctor rids the world of mortality only to be killed by rioters nostalgic for natural death. In another, the elderly pay a company to upload their minds into computers that would stimulate them with their own private afterlives

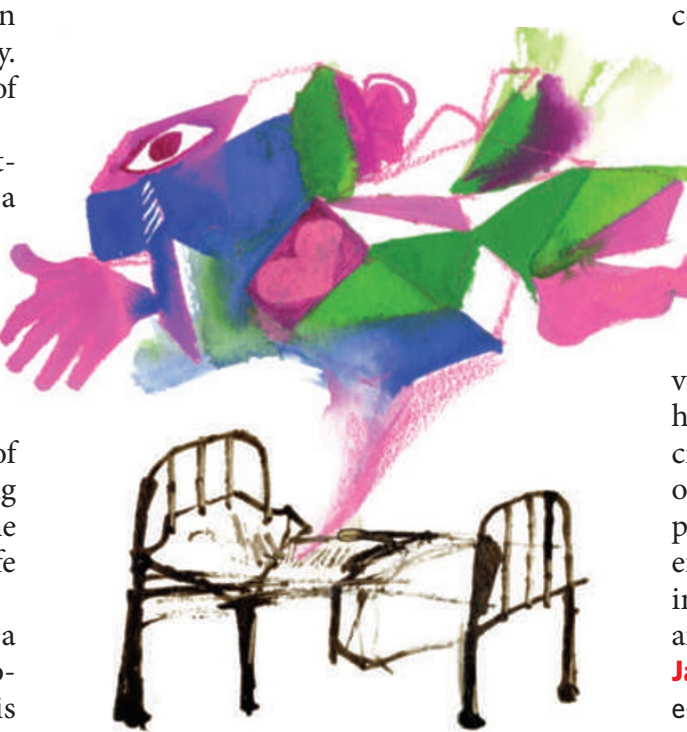

for eternity - if only the machines worked. Death is an essential part of life.

In other stories we are the malfunctioning machines, built by another species to map Earth, perform a computation or discover the meaning of life. The engineering project usually fails, but humanity flourishes nonetheless. The moral seems to be that we should look for the silver lining in our own design flaws.

Sum becomes unsettling when it turns to cosmology. A civilization, after discovering their universe to be alive, attempts to communicate with her. "We sent a sharply defined sequence of electromagnetic pulses," its citizens say, "which interacted with local magnetospheres, which influenced asteroid orbits, which nudged planets closer and farther from stars, which dictated the fate of lifeforms, which changed the gases in the atmospheres, which bent the path of light signals, all in complex interacting cascades" that "took a few hundred years ... to arrive at her consciousness". The cosmic answer, perhaps nothing more than an immune response, is the destruction of their planet, leading a survivor to conclude that "communicating with [the universe] is not impossible, but it is pointless".

Hope returns when Eagleman trades in his telescope for a microscope. There is some comfort in the idea that "when you die, you are grieved by all the atoms of which you were composed".

The best stories in Sum remind us that it is natural to want to know our place in the scheme of things. The book is a scripture of sorts, but because each myth contradicts the last, it is not a dogmatic collection. Eagleman has said that he is neither a believer nor a non-believer in the conventional religious sense. Rather, he considers himself a "possibilian", which he defines as a creed for "those that celebrate the vastness of our ignorance, are unwilling to commit to any particular made-up story, and take pleasure in entertaining multiple hypotheses". These may indeed be the qualities of a good scientist and a good storyteller.

Jascha Hoffman is a writer based in New York. e-mail: jascha@jaschahoffman.com
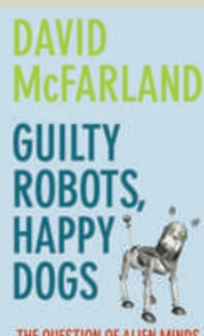

THE OUESTION OF AUEE MINOS
Guilty Robots, Happy Dogs: The Question of Alien Minds by David McFarland (Oxford Univ. Press, £7.99)

Taking a fresh angle on the question of 'alien minds' whether animal or machine - and drawing on current research in computing, robotics and animal behaviour, David McFarland offers an accessible introduction to the philosophy of the mind. He explains why intelligence may be impossible to define.

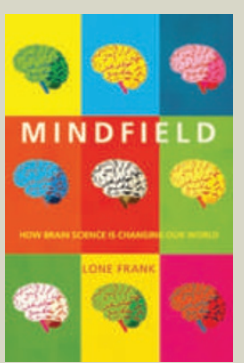

Mindfield: How Brain Science is Changing Our World

by Lone Frank

(Oneworld, \$16.95)

Lone Frank asks how neuroscience is transforming our society. By describing her own experiences while researching the book - from holding half a real brain in her hands to talking with leading scientists - she explains advances in the field for a general audience. 